\title{
AVALIAÇÃO DE DOIS SOLOS RESIDUAIS DO MUNICÍPIO DE ENCRUZILHADA DO SUL-RS PARA EMPREGO COMO CAMADA DE REVESTIMENTO PRIMÁRIO DE ESTRADAS DE TERRA
}

\author{
Leandro Olivio Nervis ${ }^{*}$, Mauricio Cruz Zaikoski ${ }^{2}$, Caroline Castilhos Rezende ${ }^{3}$ \\ ${ }^{1}$ Departamento de Engenharias, Arquitetura e Ciências Agrárias, Universidade de Santa Cruz do Sul UNISC, CEP 96815-900, Santa \\ Cruz do Sul, Rio Grande do Sul, Brasil. \\ ${ }^{2}$ Curso de Engenharia Civil, Universidade de Santa Cruz do Sul UNISC, CEP 96815-900, Santa Cruz do Sul, Rio Grande do Sul, \\ Brasil. \\ ${ }^{3}$ Curso de Engenharia Civil, Universidade de Santa Cruz do Sul UNISC, CEP 96815-900, Santa Cruz do Sul, Rio Grande do Sul, \\ Brasil.
}

*E-mail: leandron@unisc.br

\section{RESUMO}

Atualmente, os critérios para definição do material para ser utilizado no revestimento primário implicam muito mais a experiência de quem executa do que conhecimentos geotécnicos. No presente trabalho, foi realizado um estudo experimental com o objetivo de analisar dois tipos de solos com diferentes características para o possível emprego em revestimento primário. Foram realizadas coletas de amostras do subleito de uma estrada (solo 1), que é um solo residual de gnaisse, e de um solo de área de empréstimo (solo 2), residual de granito, ambas no município de Encruzilhada do Sul-RS, Brasil. Foram realizados ensaios de laboratório, tais como análise granulométrica, Limites de Atterberg (Limite de Liquidez e Limite de Plasticidade), ensaios de compactação, Índice de Suporte Califórnia (ISC), também conhecido como California Bearing Ratio (CBR), e ensaios voltados à classificação MCT (Miniatura, Compactado, Tropical). Os resultados foram analisados e discutidos, e, a partir disso, foi avaliada a aptidão dos materiais para emprego no revestimento primário de estradas de terra. Concluiu-se que o solo 1 não é apto para funcionar como camada final devido a sua baixa capacidade de suporte, demandando, portanto, camada(s) de revestimento primário. O solo 2, por sua vez, é altamente recomendado como reforço do subleito, pois se enquadra no grupo de primeira prioridade com esse fim. Porém, não é recomendado como camada final de revestimento primário devido à deficiência de fração argila.

Palavras-chave: Estradas de terra. Revestimento primário. Classificação MCT.

\section{Introdução}

O solo tem sido um dos materiais mais importantes para o homem durante toda a história. Na Engenharia Civil, um importante uso do solo é na construção de estradas, nas quais pode ser utilizado em camadas de base, sub-base ou reforço de pavimento para uma rodovia pavimentada, ou, ainda, usado como material principal em uma estrada com revestimento primário. Esse último é definido como sendo uma camada de solo com propriedades ideais, capaz de ofertar em sua superfície de rolamento o tráfego de veículos em qualquer época do ano [1].

As vias terrestres sem revestimento clássico (asfalto, concreto ou calçamento), providas ou não de revestimento primário, também conhecidas como "estradas de terra", representam aproximadamente $87 \%$ do total da malha viária nacional, totalizando mais de 1,3 milhão de quilômetros [2]. Essa expressiva representação torna notável a importância dessas vias nos contextos social e econômico. Assim, elas têm como objetivos principais fazer a interligação das malhas viárias regionais; interligar sistemas modais existentes; escoar a produção para outro sistema viário ou locais de armazenagem; e permitir o acesso rodoviário a locais onde se concentram vilarejos com pessoas carentes [3].

Geralmente, os materiais empregados no revestimento primário dessas vias não são necessariamente especificados com base em critérios técnicos objetivos, mas simplesmente selecionados de acordo com a disponibilidade ou experiências anteriores. Isso muito se deve à carência de requisitos de desempenho inteiramente consolidados e bem definidos, concebidos especificamente para tal finalidade. As publicações que propõem critérios têm apresentado diferenças substanciais entre si, muitas vezes apresentando certo antagonismo. Além disso, boa parte delas se embasa nos princípios da Mecânica dos Solos tradicional, concebidos para solos originados pelo intemperismo predominantemente físico, podendo gerar 


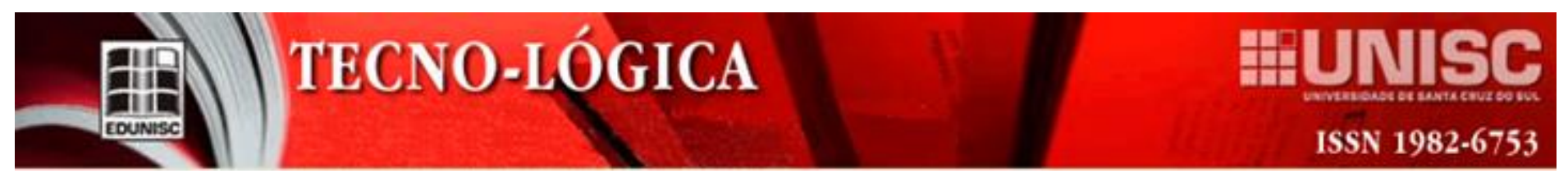

resultados ineficientes para solos originados pelo intemperismo predominantemente químico [4].

Metodologias alternativas para a seleção de materiais para utilização rodoviária, incluindo pavimentos com revestimento primário, empregáveis para ambos os tipos de solos citados no parágrafo anterior, são as classificações MCT e G-MCT. A primeira, apresentada por Nogami e Villibor [5], tem aplicação restrita a solos com partículas menores que $2 \mathrm{~mm}$. A segunda, apresentada por Alves e Villibor [6], trata-se de uma evolução da primeira, permitindo classificar solos com presença de pedregulho, na qual a letra G simboliza "material graúdo".

Observou-se que um trecho de uma estrada de terra no município de Encruzilhada do Sul-RS, que se encontra em seu leito natural, não apresenta condições satisfatórias ao usuário quando esse por ela trafega, sendo visualmente perceptível a presença de patologias como panelas e afundamentos de trilhas de rodas. Tendo em vista a importância da estrada para a região, isso serviu como motivação para que se realizasse uma avaliação, a partir de resultados experimentais, a fim de se verificar se o material que compõe a estrada e outro com potencial emprego (extraído da área de empréstimo), ambos com importante presença de pedregulho, são adequados para o emprego em revestimento primário. Assim, a presente pesquisa teve como objetivo realizar a mencionada avaliação, tomando como base a classificação GMCT, buscando identificar se o mau desempenho do trecho de estrada supracitado é explicado pela natureza do solo ou por outros fatores.

\section{Metodologia}

\subsection{Descrição do local do estudo}

O local de estudo encontra-se no município de Encruzilhada do Sul-RS, sendo a seguir apresentadas as descrições físicas, geológicas e pedológicas dos pontos de coleta das amostras de solo. Encruzilhada do Sul está localizado na região centro-sul do estado do Rio Grande do Sul, Brasil (Figura 1). Os locais onde foram coletados os solos (Figura 2) apresentam as seguintes coordenadas: para o subleito (Solo 1), 30 33'53,73S" (latitude) e $52^{\circ} 30^{\prime} 23,23^{\prime \prime} \mathrm{W}$ (longitude), e para o solo da área de empréstimo com potencial uso no revestimento primário (Solo 2) $30^{\circ} 32^{\prime} 31,00^{\prime \prime} \mathrm{S}$ (latitude) e 52³0’25,21”W (longitude).

O município de Encruzilhada do Sul está incluso no Bioma Pampa, o qual é caracterizado pela presença de vegetação rasteira, com relevo suavemente ondulado, formado por coxilhas e também pela vasta diversidade de fauna e flora ainda não exploradas [9]. O município apresenta clima subtropical, de classificação mesotérmico úmido, sendo localizado na província geomorfológica denominada de Escudo Sul-Rio-Grandense, ou Serra do Sudeste. No local, a temperatura média anual é de $17^{\circ} \mathrm{C}$ e a precipitação pluviométrica média anual é de 1500 a $1600 \mathrm{~mm}$ [10].

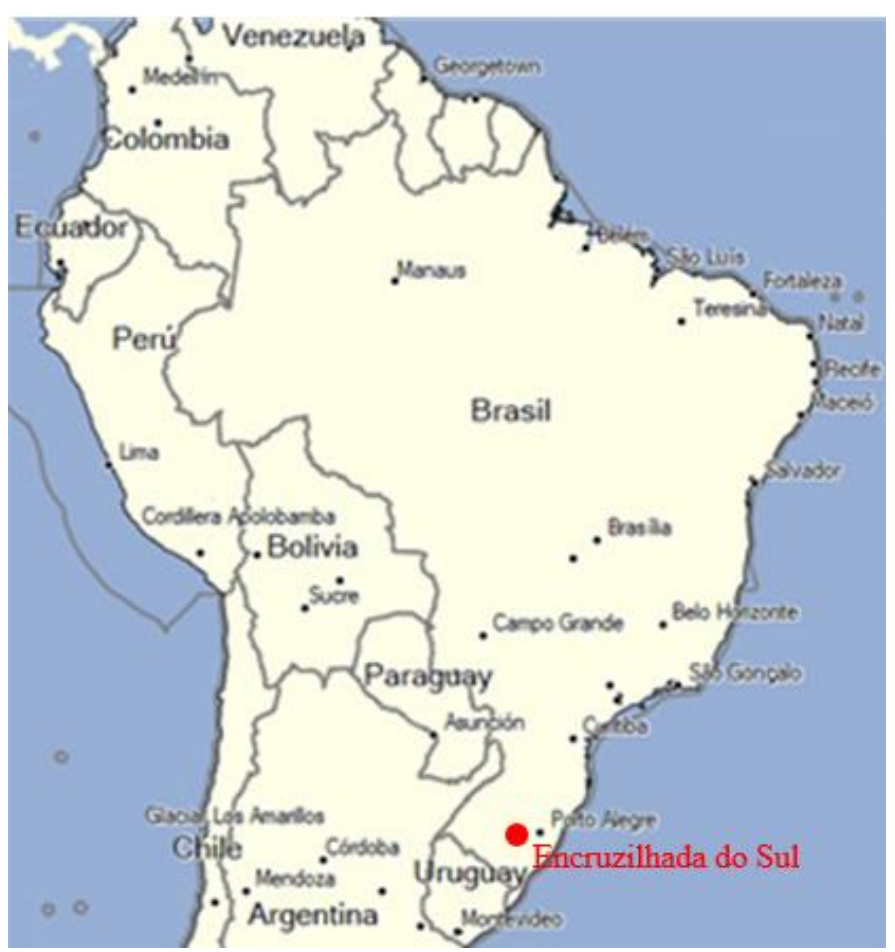

Figura 1 - Localização do Município de Encruzilhada do Sul-RS [7]

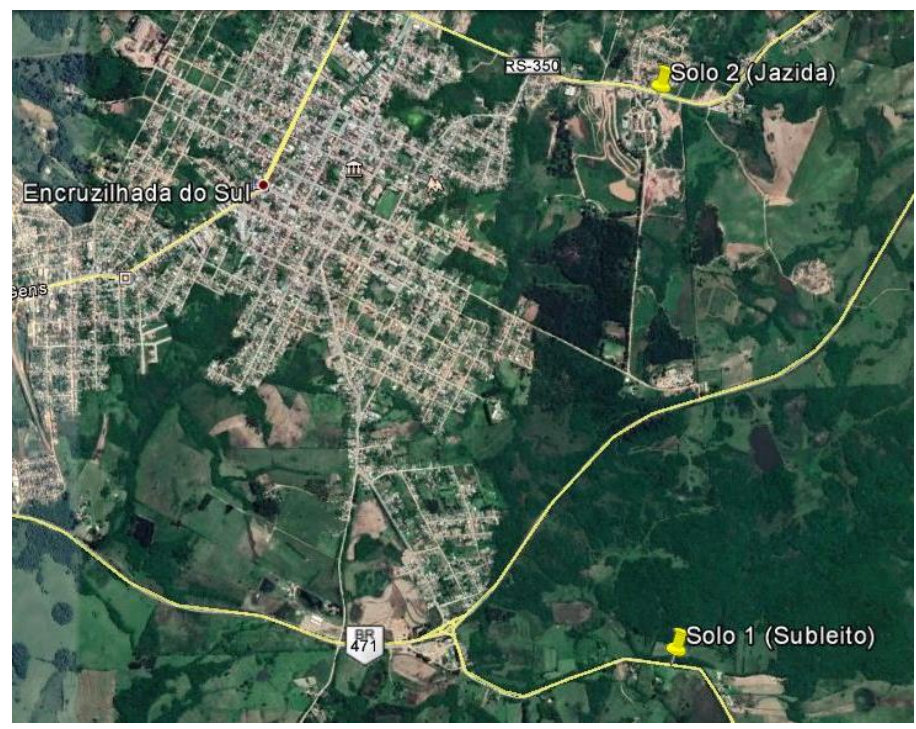

Figura 2 - Localização dos pontos de coleta e amostra dos solos [8]

Quanto à geologia, os pontos de coleta de amostras dos solos 1 e 2 situam-se no mapa geológico [11], respectivamente nas regiões identificadas pelos códigos PP2vc e NP3 $\gamma$ ese (Figura 3). A primeira é composta por gnaisse pelítico e quartzo-feldspático, e a segunda por monzogranito porfirítico a sienogranito. 


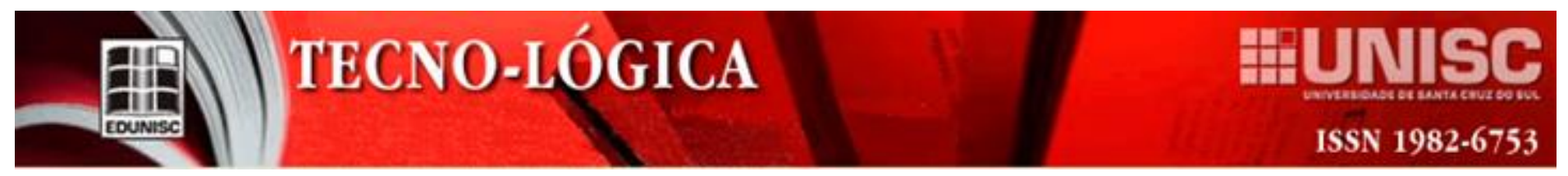

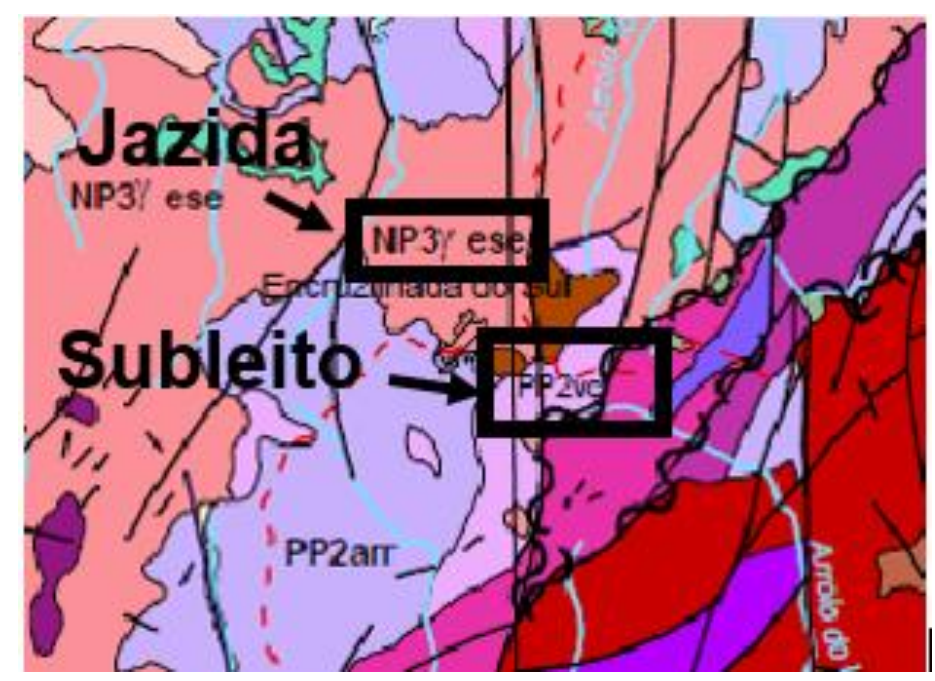

Figura 3 - Localização no mapa geológico dos pontos de coleta de amostras [11] (Adaptado de Serviço Geológico do Brasil)

Com relação à pedologia, os locais de onde foram extraídos os solos 1 e 2 ficam enquadrados, respectivamente, nas classes argissolo vermelho-amarelo distrófico úmbrico (unidade Camaquã - PVAd4) e neossolo regolítico distro-úmbrico líptico ou típico (unidade Pinheiro Machado- RRdh2). Os argissolos são solos geralmente profundos a muito profundos, variando de bem drenados a imperfeitamente drenados, apresentando um perfil com uma sequência de horizontes A-Bt-C ou A-E-Bt-C, em que o horizonte Bt é do tipo textural. Esse horizonte, do qual foi extraído o Solo 1, é significativamente mais argiloso do que os horizontes superiores. Os neossolos são rasos ou profundos, e o perfil em questão apresenta uma sequência A-Cr-R, sendo o solo extraído do horizonte Cr. Esse horizonte, do qual foi extraído o solo 2, é constituído por rocha alterada, pouco afetada por processos de intemperização [12].

\subsection{Coleta de amostras}

As amostras dos Solos 1 e 2 referidos anteriormente foram do tipo deformadas, sendo extraídas manualmente com o auxílio de uma pá de corte e acondicionadas em sacos e, na sequência, transportadas até o Laboratório de Solos da Universidade de Santa Cruz do Sul - UNISC. A quantidade coletada de cada solo foi de aproximadamente $50 \mathrm{Kg}$ de material.

O Solo 1 foi extraído do barranco da estrada, numa cota equivalente àquela do subleito, buscando-se com isso que ele fosse representativo dessa camada e isento de eventuais impurezas. A profundidade em relação à superfície original foi de $0,8 \mathrm{~m}$, correspondendo ao horizonte B do terreno (Figura 4). A amostra do Solo 2 foi coletada diretamente da área de empréstimo, numa profundidade de aproximadamente $2,5 \mathrm{~m}$, pertencente ao horizonte $\mathrm{C}$ do perfil (Figura 5).

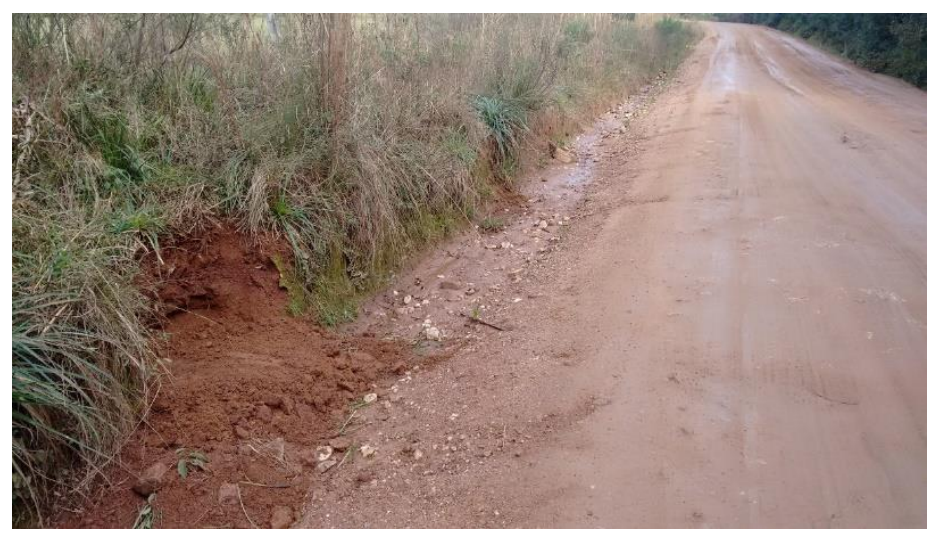

Figura 4 - Posição da coleta de amostra do Solo 1 (Subleito)

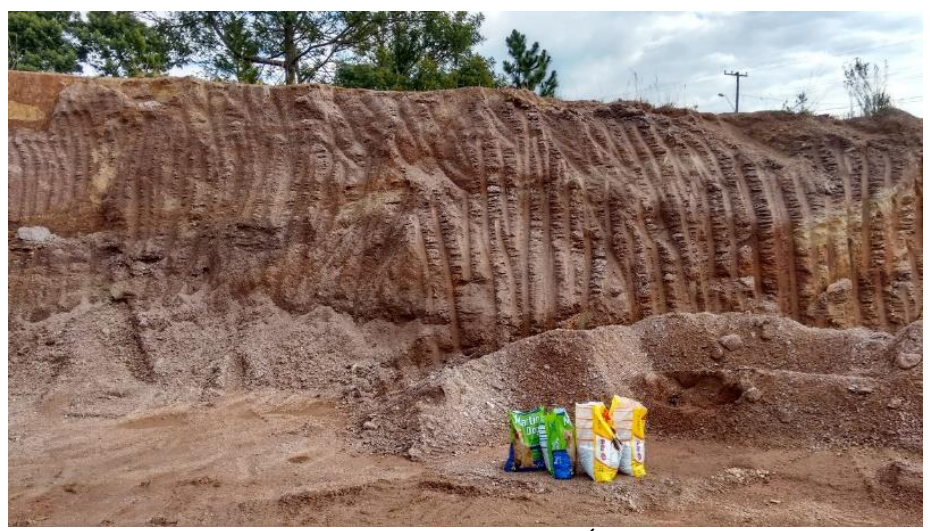

Figura 5 - Posição da coleta de amostra do Solo 2 (Área de Empréstimo)

\subsection{Realização de ensaios de laboratório}

Foram realizados ensaios de caracterização (granulometria, peso específico dos grãos e limites de Atteberg) para os dois solos estudados. Os procedimentos empregados seguiram as recomendações das normas NBR 6457:2016 [13], NBR 7181:2016 [14], NBR 6458:2016 [15], NBR 6459:2016 [16] e NBR 7180:2016 [17].

Também foram realizados ensaios de compactação para ambos os solos, empregando-se a energia normal de Proctor, com a finalidade de obter a umidade ótima e o peso específico aparente seco máximo para cada solo nessa energia. Para tal, seguiram-se os procedimentos recomendados pelas normas NBR 6457:2016 [13] e NBR 7182:2016 [18]. Em função da granulometria dos solos, obedecendo-se às prescrições da NBR 6457:2016 [13], foi utilizado nos ensaios o cilindro grande.

Na sequência, foi moldado um corpo de prova de cada solo para serem submetidos a ensaios de ISC. Na moldagem buscou-se atingir as condições ótimas de compactação da energia normal de Proctor, tomando-se como base os parâmetros obtidos nos ensaios de compactação. $\mathrm{Na}$ realização dos ensaios foram seguidas as normas NBR 6457:2016 [13] e NBR 9895:2016 [19]. Registra-se 
aqui a introdução de uma adaptação no procedimento de determinação da expansão em relação ao prescrito na norma, ao optar-se por realizar o ensaio sem sobrecarga. Justifica-se isso pela intenção de buscar ao máximo simular a situação real, em que as camadas, diferentemente do caso de um pavimento convencional, não possuem significativa sobrecarga.

Por fim, foram realizados os ensaios voltados à classificação MCT da fração dos solos passantes na peneira de 2 $\mathrm{mm}$, quais sejam o ensaio de compactação Mini-MCV e o ensaio de perda de massa por imersão. Para tal, foi seguido o procedimento da norma DNER-CLA 259/1996 [20].

\subsection{Qualificação dos solos estudados para emprego como revestimento primário}

A qualificação dos dois solos estudados no presente trabalho quanto a sua empregabilidade como revestimento primário de estradas de terra foi embasada na sua classificação GMCT, no seu comportamento quanto à expansão e na sua capacidade de suporte representada pelo ISC.

Devido à forte ocorrência de solos com presença de pedregulho, surgiu a classificação G-MCT com a finalidade de avaliar o comportamento desses solos, suprindo, assim, a limitação da classificação MCT, que fica restrita a solos predominantemente finos. Essa classificação se fundamenta em dois aspectos: definição dos tipos granulométricos do solo integral e classificação MCT da fração de solo que passa na peneira de 2 mm. Os tipos granulométricos são os seguintes: Ps (pedregulho com solo), Sp (solo com pedregulho) e Gf (material granular com média a elevada quantidade de finos). Eles são obtidos a partir do enquadramento gráfico (Figura 5) das porcentagens que passam nas peneiras de $0,075 \mathrm{~mm}$ e $2 \mathrm{~mm}$, cujos valores são obtidos nos ensaios de granulometria. Combinando-se esses três tipos granulométricos com os sete grupos da classificação MCT, têm-se 21 possibilidades de classificação. Dentre esses grupos, os mais indicados são os designados como Ps-LA' e Sp-LA', seguidos dos Ps-LG' e Sp-LG'. Na terceira, quarta e quinta ordem de prioridade, têm-se, respectivamente, os grupos Gf-LA', Gf-LG' e Gf-LA. Os demais grupos não são recomendados para uso [6].

Quanto à expansão, o Manual de Conservação Rodoviária do DNIT [1] recomenda que não sejam empregados no revestimento primário materiais que apresentarem valores maiores do que $2 \%$.

Os valores mínimos de ISC estabelecidos pelas especificações do DER/PR [21] e do Departamento de Transportes da República da África do Sul (Draft TRH 20 - The Structural Design, Construction and Maintenance of Unpaved Roads) [22] para materiais a serem empregados em revestimento primário são, respectivamente, de $13 \%$ e $15 \%$.

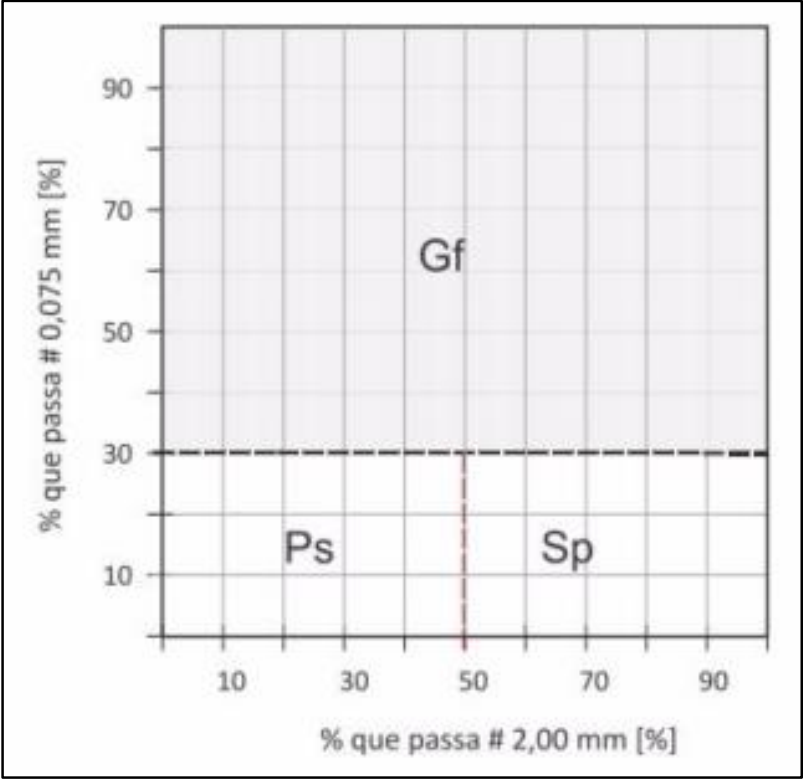

Figura 5 - Gráfico para a definição do tipo granulométrico da classificação G-MCT [6]

\section{Resultados e discussões}

\subsection{Caracterização dos solos estudados}

Na Figura 6 são apresentadas as curvas granulométricas dos Solos 1 e 2 e na Tabela 1 um resumo de sua caracterização.

Analisando-se a curva granulométrica do subleito (Solo 1), constata-se que o material apresenta média quantidade de argila, importante quantidade de silte e considerável quantidade de areias e pedregulhos, classificando-se como areia pedregulho-argiloso. Já o material da área de empréstimo (solo 2) apresentou baixa quantidade de argila, pouca quantidade de silte, média de areia e grande porcentagem de pedregulho, classificando-se como pedregulho arenoso.

O Solo 1, conforme exposto anteriormente, foi extraído de um horizonte Bt de um argissolo, mais argiloso que os superiores. Embora sendo arenoso, ele apresenta boa porcentagem de argila, o que é coerente com a pedologia. O que impede de ser mais argiloso é o fato de a rocha ser um gnaisse, a qual é rica em quartzo e possui textura mais graúda.

O Solo 2 foi extraído de um horizonte $\mathrm{Cr}$, que guarda relação íntima com a rocha, a qual, por sua vez, é um granito, rica em quartzo e de granulometria grossa. Portanto, a lógica aponta um solo de granulometria graúda, que está coerente com o resultado que se obteve no ensaio. 


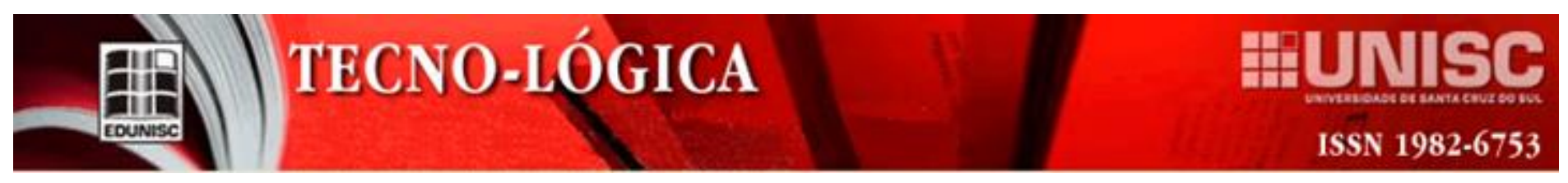

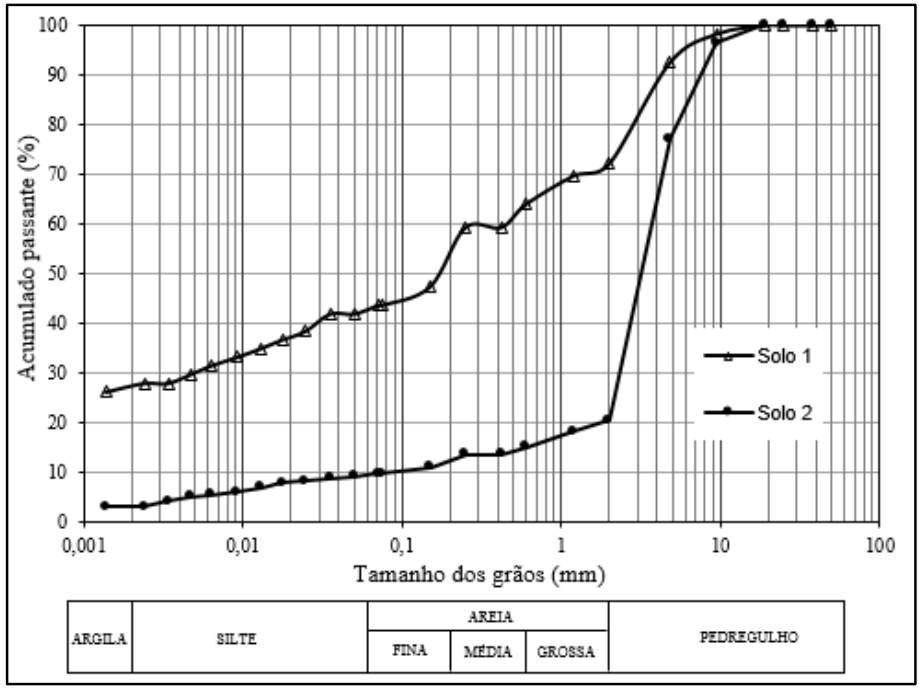

Figura 6 - Curvas granulométricas dos solos estudados

Tabela 1. Principais características físicas dos solos estudados

\begin{tabular}{|c|c|c|c|}
\hline \multirow{2}{*}{\multicolumn{2}{|c|}{ Propriedades }} & \multicolumn{2}{|c|}{ Materiais } \\
\hline & & Solo 1 & Solo 2 \\
\hline \multirow{5}{*}{ 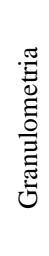 } & Pedregulho (2mm < $<\leq 60 \mathrm{~mm})$ & $28 \%$ & $79 \%$ \\
\hline & Areia $(0,06 \mathrm{~mm}<\Phi \leq 2 \mathrm{~mm})$ & $32 \%$ & $12 \%$ \\
\hline & Silte $(0,002 \mathrm{~mm}<\Phi \leq 0,06 \mathrm{~mm})$ & $14 \%$ & $5 \%$ \\
\hline & Argila $(\Phi \leq 0,002 \mathrm{~mm})$ & $26 \%$ & $4 \%$ \\
\hline & $\begin{array}{l}\text { Classificação granulométrica } \\
\text { segundo a NBR 6502:1995 }\end{array}$ & $\begin{array}{l}\text { Areia pedregulho- } \\
\text { argilosa }\end{array}$ & $\begin{array}{l}\text { Pedregulho } \\
\text { arenoso }\end{array}$ \\
\hline \multicolumn{2}{|c|}{$\begin{array}{l}\text { Peso específico real dos grãos } \\
\left(\mathrm{kN} / \mathrm{m}^{3}\right)\end{array}$} & 24,4 & 26,9 \\
\hline \multirow{4}{*}{$\begin{array}{l}\frac{0}{0} \\
. \frac{0}{0} \\
.00 \\
\frac{0}{2} \\
\frac{\pi}{2}\end{array}$} & Limite de Liquidez - LL & $29 \%$ & $31 \%$ \\
\hline & Limite de Plasticidade - LP & $27 \%$ & NP \\
\hline & Índice de Plasticidade - IP & $2 \%$ & $0 \%$ \\
\hline & $\begin{array}{l}\text { Classificação segundo Burmister } \\
\text { (1949) apud Das e Sobhan } \\
\text { (2014) }\end{array}$ & $\begin{array}{l}\text { Fracamente } \\
\text { plástico }\end{array}$ & Não plástico \\
\hline \multicolumn{2}{|c|}{ Classificação SUCS } & $\begin{array}{c}\text { SM } \\
\text { Areia siltosa }\end{array}$ & $\begin{array}{c}\text { GP-GM } \\
\text { Pedregulho } \\
\text { siltoso mal } \\
\text { graduado }\end{array}$ \\
\hline \multicolumn{2}{|c|}{ Classificação da AASHTO } & $\begin{array}{c}\text { A-4 } \\
\text { Solo siltoso }\end{array}$ & $\begin{array}{c}\text { A-1a } \\
\text { Solos grossos } \\
\text { (pedregulhos) }\end{array}$ \\
\hline
\end{tabular}

Observa-se que as classificações tradicionais apresentam pouca coerência com a real característica do solo, em se tratando de solos tropicais. Há comportamentos peculiares devido a diversos fatores. A experiência em laboratório e em campo revela que os limites fixados para LL e LP em normas tradicionais já não se aplicam nessas condições, uma vez que se verificou a existência de solos com mesmo LL e IP, mas com expansibilidades completamente distintas, o que prejudica a validade de classificações geotécnicas como a AASHTO, por exemplo. Além disso, a porcentagem passante na peneira $0,075 \mathrm{~mm}$ também apresenta grande variabilidade em sua constituição a depender do tipo genético do solo, o que faz com que limites fixados nas classificações sejam rígidos e levem a classificações precipitadas [5].

3.2 Parâmetros de compactação, capacidade de suporte $e$ propriedades de expansão dos solos estudados

Nas Figuras 7 e 8 são apresentadas as curvas de compactação dos Solos 1 e 2, respectivamente, e na Tabela 2 são apresentados os valores dos parâmetros de compactação de ambos os solos.

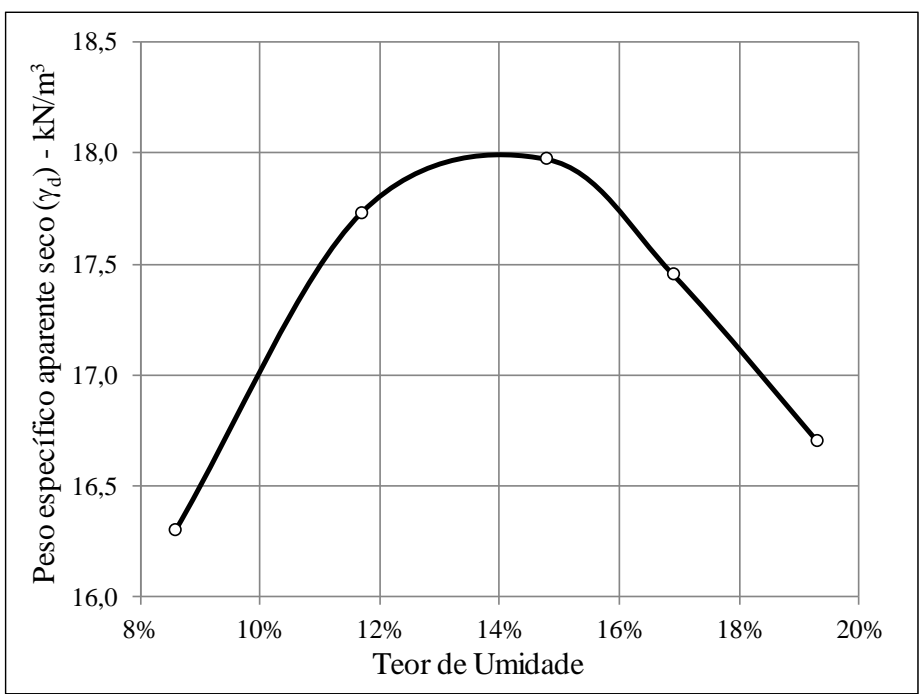

Figura 7 - Curva de Compactação do Solo 1

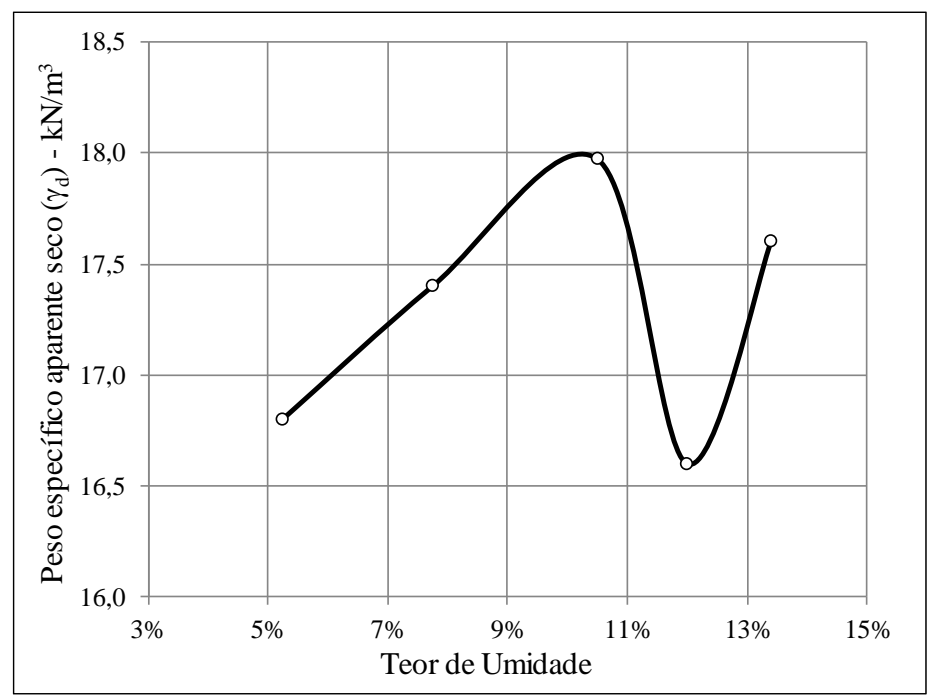

Figura 8 - Curva de Compactação do Solo 2 
Tabela 2. Parâmetros de compactação dos solos estudados

\begin{tabular}{l|c|c}
\hline \multirow{1}{*}{ Parâmetros } & \multicolumn{2}{c}{ Materiais } \\
\cline { 2 - 3 } & Solo 1 & Solo 2 \\
\hline $\begin{array}{l}\text { Peso específico aparente } \\
\text { seco máximo - } \gamma_{\mathrm{dmax}}\left(\mathrm{kN} / \mathrm{m}^{3}\right)\end{array}$ & 18,0 & 18,0 \\
Umidade ótima - $\mathrm{w}_{\mathrm{ot}}$ & $14,0 \%$ & $10,3 \%$ \\
\hline
\end{tabular}

Analisando-se os resultados obtidos, destaca-se, inicialmente, que a curva de compactação do Solo 2 apresentou um formato irregular em relação ao formato típico. Sabe-se que eventualmente isso é de ocorrência possível, principalmente em solos pedregulhosos. Verifica-se que o conjunto de pares de valores (umidade ótima e peso específico aparente seco máximo) obtidos estão dentro da ordem de grandeza para solos granulares [23].

Na Tabela 3 são apresentados os valores obtidos para o ISC e expansão dos dois solos estudados.

Tabela 3. ISC e expansão dos solos estudados

\begin{tabular}{l|c|c}
\hline \multirow{2}{*}{ Propriedades } & \multicolumn{2}{c}{ Materiais } \\
\cline { 2 - 3 } \multicolumn{1}{c|}{ Solo 1 } & Solo 2 \\
\hline ISC & $3 \%$ & $20 \%$ \\
Expansão & $0,29 \%$ & $0,15 \%$ \\
\hline
\end{tabular}

Verificou-se que o Solo 1 apresentou um ISC de 3\%, o que é considerado muito baixo, estando muito aquém dos valores mínimos recomendados pela literatura (13\% e 15\%) [5]. Já o Solo 2 apresentou um ISC de $20 \%$, atendendo tal exigência. Isso implica que o solo do subleito não poderá funcionar como camada final, demandando uma camada de revestimento primário, tendo em vista sua baixa capacidade de suporte.

Com relação à expansão, os solos que apresentam valores abaixo de $0,5 \%$ são classificados como de baixa expansão [5]. Assim, os dois solos estudados classificam-se como tal, atendendo também, consequentemente, o limite de $2 \%$ recomendado pela especificação do DNIT [1], conforme exposto em 2.4.

\subsection{Classificação MCT da fração fina dos solos estudados}

Na Figura 9 é apresentada a classificação MCT da fração fina dos solos estudados.

Verifica-se que a fração fina do Solo 1 ficou com classificação muito próxima das fronteiras de NA', LA' e LG', não sendo possível determinar uma classificação determinística, pois qualquer pequena heterogeneidade do solo em razão do fator espacial pode repercutir em resultados diferentes. Já a fração fina do solo 2 classificou-se como NA'.

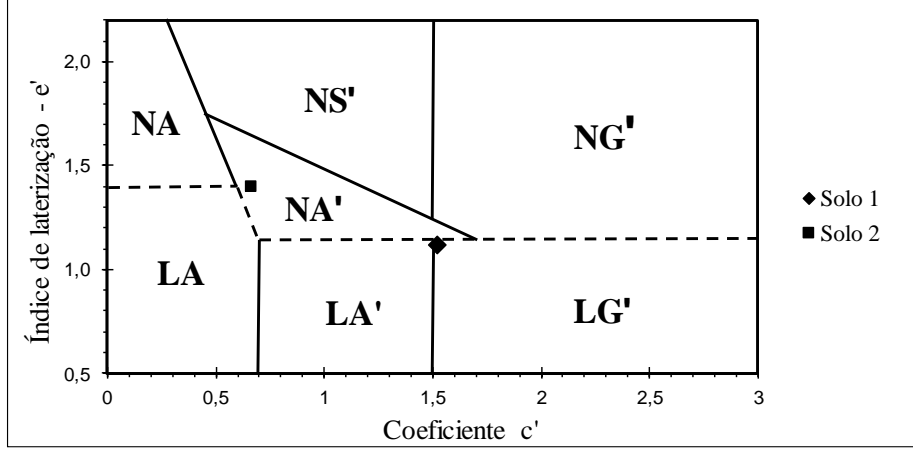

Figura 9 - Classificação MCT da fração fina dos solos estudados

\subsection{Classificação G-MCT dos solos estudados e qualificação} quanto ao seu emprego como revestimento primário

O Solo 1 apresentou uma classificação G-MCT na transição entre os grupos Gf-LG', Gf-LA' e Gf-NA'. De qualquer forma, conforme exposto anteriormente, o seu emprego como camada final de pavimento com revestimento primário já é previamente descartado devido a sua baixa capacidade de suporte representada pelo valor de ISC de $3 \%$.

Já o Solo 2 pertence ao grupo Ps-NA', não sendo recomendado seu emprego como revestimento primário. Isso ocorre porque a fração fina é deficiente em argila de comportamento laterítico, recaindo num grupo da classificação MCT vulnerável a sofrer desagregação. Todavia, como reforço do subleito é altamente indicado, pois se enquadra no grupo de primeira prioridade [6].

\section{Conclusões}

A partir dos estudos experimentais realizados, concluiuse que o Solo 1 não é apto para funcionar como camada final devido a sua baixa capacidade de suporte, expresso pelo valor de ISC muito baixo, demandando, portanto, camada(s) de revestimento primário. O Solo 2 pode ser empregado em camadas de reforço, mas não é recomendado como camada final de revestimento primário.

Observaram-se incoerências de resultados das classificações tradicionais com as características dos solos e com a classificação MCT, validando o que é alertado por Nogami e Villibor [5] quando se tratam de solos desenvolvidos em ambientes tropicais e subtropicais. Portanto, recomenda-se a priorização de uso das classificações MCT e G-MCT quando se tratar desse tipo de solo.

A pesquisa demonstrou que o ISC por si só é insuficiente para qualificar um material para revestimento primário, porque o Solo 2, embora tenha apresentado um ISC razoável, devido à 
deficiência de presença de argila de comportamento laterítico, tende a sofrer processos de desagregação.

Vislumbra-se a realização de trabalhos futuros que promovam a melhoria das características dos materiais, visando a torná-los aptos a serem empregados em revestimento primário. Isso envolve estudos incorporando outros solos locais, assim como aditivos químicos como cal ou cimento.

\section{EVALUATION OF TWO RESIDUAL SOILS OF THE ENCRUZILHADA DO SUL - RS (BRAZIL) FOR USE AS WEARING COURSE OF UNSURFACED GRAVEL ROADS}

\begin{abstract}
Currently, the criteria for defining the material to be used in the wearing course of unsurfaced gravel roads lie much more in the experience of those who carry out the work than based on geotechnical knowledge. In the present paper, an experimental study was conducted with the aim to analyze two types of soils with different characteristics for their possible use in wearing course layers. Samples were collected from the subgrade of a road (soil 1), which is residual soil of gneiss, and soil from a loan site (soil 2), granite residual soil, both in the municipality of Encruzilhada do Sul-RS, Brazil. Laboratory tests were conducted as follows: granulometric analysis, Atterberg Limits (Liquid Limit and Plasticity Limit), compaction tests, California Bearing Ratio (CBR) and tests aimed at the MCT classification (Miniature, Compacted, Tropical). The results were analyzed and discussed and, from this, the materials for wearing course layers were rated. It was concluded that soil 1 is not appropriate to be used as final layer because of its low bearing capacity, thus requiring a wearing course layer. Soil 2, in turn, is highly recommended as subgrade reinforcement, as it fits into the first priority group for this purpose. However, it is not recommended as final layer due to its deficient clay content.
\end{abstract}

Keywords: Unsurfaced gravel roads. Primary coating, MCT classification.

\section{Referências}

[1] BRASIL. Departamento Nacional de Infra- Estrutura de Transportes - DNIT. Diretoria de Planejamento e Pesquisa. Coordenação Geral de Estudos e Pesquisas. Instituto de Pesquisas Rodoviárias - IPR. Manual de conservação rodoviária. 2005. Disponível

$<$ http://www1.dnit.gov.br/arquivos_internet/ipr/ipr_new/manuais/Manual\%20de \%20Conservacao\%20Rodoviaria.pdf>. Acesso em: 07 mai. 2017.

[2] Site oficial do Departamento Nacional de Infraestrutura de Transportes - DNIT. Disponível em: http://www.dnit.gov.br/sistema-nacional-de-viacao/sistemanacional-de-viacao . Acesso em: 12 abr. 2018.
[3] BRASIL. Departamento Nacional de Infra-Estrutura de Transportes - DNIT. Diretoria de Planejamento e Pesquisa. Coordenação Geral de Estudos e Pesquisas. Instituto de Pesquisas Rodoviárias - IPR. Diretrizes básicas para elaboração de estudos e projetos rodoviários, DNIT. 2006. Disponível em: <http://www1.dnit.gov.br/arquivos_internet/ipr/ipr_new/manuais/diretrizes_basic as_instrucoes_servicos.pdf>. Acesso em: 28 mar. 2017.

[4] NERVIS, Leandro Olivio. Identificação e discussão dos mecanismos de degradação de pavimentos com revestimento primário. 2016. 267 f. Tese (Programa de Pós-Graduação em Engenharia Civil - Doutorado) - Universidade Federal do Rio Grande do Sul, Porto Alegre. 2016.

[5] NOGAMI, J. S.; VILLIBOR, D. F.; Pavimentação de baixo custo com solos lateríticos; São Paulo: Villibor, 1995. 213p

[6] ALVES, D. M. L..; VILLIBOR, D. F.. Classificação de solos tropicais de granulação fina e grossa. Revista ABPV Pavimentação, 43. Ed., p. 78. Disponível em: <https://issuu.com/revistapavimentacao/docs/revista_43> Acesso em: 29 jul. 2017.

[7] Site oficial sobre o Projeto COCAR-DL/PSM, organizado por Thundercel. Disponível em: http://cocardl.com.br/viewtopic.php?f=52\&t=458 . Acesso em: 12 abr. 2018.

[8] GOOGLE. Google Earth. Versão 7.3.1.4507. 2018.

[9] Site sobre o atlas sócioeconômico do Rio Grande do Sul, organizado pela Secretaria de Planejamento, Orçamento e Gestão do Rio Grande do Sul. Disponível em: https://atlassocioeconomico.rs.gov.br/biomas. Acesso em: 25 mar. 2018.

[10] RIO GRANDE DO SUL. Secretaria de Planejamento e Gestão RS. Governo do Rio Grande do Sul. Informações sobre Geografia Física. Disponível em: $<$ http://www1.seplag.rs.gov.br/atlas/imprimir.asp?cod_conteudo=1366>. Acesso em: 25 mar. 2017.

[11] BRASIL. CPRM - Serviço Geológico do Brasil. Ministério de Minas e Energia (Org.). Carta Geológica Regional. 2006. Disponível em <http://www.cprm.gov.br/publique/Geologia/Geologia-Basica/Cartografia Geologica-Regional-624.html>. Acesso em: 10 set. 2017.

[12] STRECK, E. V. et al. Solos do Rio Grande do Sul. 2. Ed., rev. e ampl. Porto Alegre: EMATER/UFRGS, 2008. 222p

[13] Associação Brasileira De Normas Técnicas. NBR 6457: Amostras de solo Preparação para ensaios de compactação e ensaios de caracterização Procedimento. Rio de Janeiro, 2016.

[14] Associação Brasileira De Normas Técnicas. NBR 7181: Solo - Análise granulométrica. Rio de Janeiro, 2016.

[15] Associação Brasileira De Normas Técnicas. NBR 6458: Grãos de pedregulho retidos na peneira de abertura 4,8 mm - Determinação da massa específica, da massa específica aparente e da absorção de água. Rio de Janeiro: ABNT, 2016.

[16] Associação Brasileira De Normas Técnicas. NBR 6459: Solo - Determinação do limite de liquidez. Rio de Janeiro: ABNT, 2016.

[17] Associação Brasileira De Normas Técnicas. NBR 7180: Solo - Determinação do limite de plasticidade. Rio de Janeiro, 2016. 


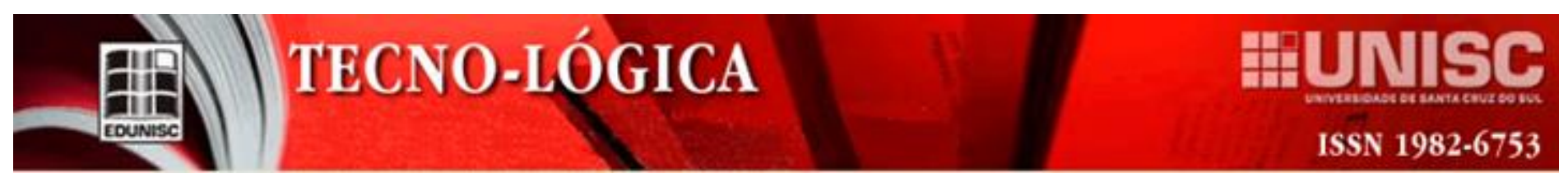

[18] Associação Brasileira De Normas Técnicas. NBR 7182: Solo - Ensaio de compactação. Rio de Janeiro, 2016.

[19] Associação Brasileira De Normas Técnicas. NBR 9895: Solo - Índice de suporte Califórnia (ISC) - Método de ensaio. Rio de Janeiro, 2016.

[20] BRASIL. Departamento Nacional de Estradas de Rodagem - DNER-CLA. Classificação de solos tropicais para finalidades rodoviárias. 1996. Disponível em: <http://ipr.dnit.gov.br/normas-e-manuais/normas/classificacao-cla/dner-cla25996.pdf>. Acesso em: 12 jun. 2017.

[21] PARANÁ. Departamento de Estradas de Rodagem do Estado do Paraná DER/PR. Especificação de serviço rodoviário. 2005. Disponível em: <http://www.der.pr.gov.br/>. Acesso em: 07 mai. 2017.

[22] PAIGE-GREEN, P. Draft TRH 20 - The Structural Design, Construction and Maintenance of Unpaved Roads. Pretoria, Departament of Transport of the Republic South Africa, 1990. Disponível em: <http://www.nra.co.za/content/Blogin/22.pdf>. Acesso em: 12 jun. 2017.

[23] PINTO, C. S.; Curso básico de mecânica dos solos: em 16 aulas. 3. Ed. São Paulo: Oficina de Textos, 2006. 355p. 